\title{
The Role of Oral Contraceptive Pills on Increased Risk of Breast Cancer in Iranian Populations: A Meta-analysis
}

\author{
Ali Soroush ${ }^{1}$, Negin Farshchian ${ }^{2}$, Saeid Komasi ${ }^{3}$, Neda Izadi ${ }^{4}$, Nasrin Amirifard ${ }^{2}$, Afshar Shahmohammadi ${ }^{3}$ \\ ${ }^{1}$ Lifestyle Modification Research Center, Imam Reza Hospital, Kermanshah University of Medical Sciences, ${ }^{2}$ Cancer Research Center, Imam Reza \\ Hospital, Kermanshah University of Medical Sciences, ${ }^{3}$ Clinical Research Development Center, Imam Reza Hospital, Kermanshah University of Medical \\ Sciences, ${ }^{4}$ HSR unit of Treatment Deputy, Kermanshah University of Medical Sciences, Kermanshah, Iran
}

\begin{abstract}
Background: Cancer is one of the main public health issues in the world. Breast cancer is one of the most common types of cancer among women. It is also the second cause of mortality in women. The association between the use of oral contraceptive pills and breast cancer is controversial and a main issue in public health. Some findings have shown that taking these pills does not have a significant effect in increasing the risk of breast cancer, while others have confirmed the carcinogenic effect of these products. These contradictory findings necessitated this meta-analysis, through of all correlated studies in Iran.

Methods: All published studies were considered from June 2000 until June 2015, using reliable Latin databases like PubMed, Google Scholar, Google search, Scopus, and Science Direct, and Persian database like SID, Irandoc, IranMedex, and Magiran. Finally, 26 papers were selected: 24 studies were case control while two were population based studies. A total of 26 papers with 46,260 participants were assessed since 2001.

Results: Overall estimate of OR for the effect of oral contraceptive pills on breast cancer is $1.521(\mathrm{Cl}=1.25-1.85)$, which shows that the intervention group had more chance $(52 \%)$ compared to the control group $(P=0.001)$. Using these pills increased the risk of breast cancer up to 1.52 times.

Conclusions: Because of directly increasing levels of estrogen and the role of estrogen in gaining weight indirectly, oral contraceptive pills can stimulate the occurrence of breast cancer. More studies should be conducted for controlling the period of pill use.

(J Cancer Prev 2016;21:294-301)
\end{abstract}

Key Words: Breast neoplasms, Oral contraceptive, Meta-analysis, Iran

\section{INTRODUCTION}

Breast cancer is one of the main public health issues in the world. Incidence of the health problem is growing in majority of countries and, despite all measures to deal with the disease, the next 20 years will witness considerable increase in incidence of the disease. ${ }^{1}$ Breast cancer is one of the most common types of cancer among women. It is also the second cause of mortality in women. Every year, about 1.4 million women are diagnosed with breast cancer and more than 450,000 die due to the disease. ${ }^{2,3}$ In developing countries, breast cancer is the most prevalent type of cancer among women aged between 20 to 56 years and one of the main causes of death in the world, accounting for $23 \%$ of all cancer cases and $14 \%$ of all mortalities. ${ }^{4.5}$ According to statistics, one in every eight women suffers from breast cancer. ${ }^{6}$ The incidence of breast cancer varies in different parts of the world, from 10.3 per 1,000 women in Southern Africa to 123.6 per 1,000 women in Central and Eastern Europe and 256.2 per 1,000 women in Northern America. It exhibits high incidence (more than 793.7 per 1,000 women) in more developed countries and low incidence in undeveloped countries (less than 40 per 1,000 women in Africa) and developed countries (less than 20 per 1,000

Received September 28, 2016, Revised November 29, 2016, Accepted December 1, 2016

Correspondence to: Afshar Shahmohammadi

Clinical Research Development Center, Imam Reza Hospital, Kermanshah University of Medical Sciences, Parastar Boulevard, Kermanshah 9883 , Iran Tel: +98-833-4276299, Fax: +98-833-4276299, E-mail: afsharshahmohammadi@yahoo.com

Copyright (C) 2016 Korean Society of Cancer Prevention

(c) This is an Open Access article distributed under the terms of the Creative Commons Attribution Non-Commercial License (http://creativecommons.org/licenses/by-nc/4.0) which permits unrestricted non-commercial use, distribution, and reproduction in any medium, provided the original work is properly cited. 
women in Australia/New Zealand). ${ }^{7}$ In comparison to the developed countries of the world, breast cancer in Asian countries has less prevalence, but is one of the main types of cancer in Asian women. ${ }^{8}$ Breast cancer with the incidence of 24 per 100,000 women is the most prevalent cancer among Iranian women. However, incidence of 24 per 100,000 cases has one of the lowest prevalence of breast cancer in the world. With regard to changes in the patterns of risk factors and population, breast cancer is expected to increase drastically in Iran, over the next decades. ${ }^{9,10}$

Many studies have been conducted to investigate the relationship between risk factors and the prevalence of breast cancer. Some of these factors are: age of menarche, age at first pregnancy, multiple pregnancies, family history of breast cancer, genetic factors, alcohol, and nutrition. Although the severity of some risk factors have been validated by stronger evidences, detailed studies have been conducted in this field, especially in Western societies. ${ }^{11,12}$ Some risk factors like family history and genetics are uncontrollable but other factors like lifestyle, smoking, obesity, and nutrition can be controlled. ${ }^{13}$ The association between the use of oral contraceptive pills (OCPs) and breast cancer is controversial and a main issue in public health. ${ }^{14}$ Among contraceptive methods, hormonal medicines are the most commonly used methods. Today, two-third of American women use OCPs. ${ }^{15,16}$ In several hypotheses about the mechanism by which contraceptive pills influence breast cancer, one highlights the relationship between the pills and gaining weight. Cleary and Grossmann ${ }^{17}$ argued that using the pills was a factor effective on gaining weight and obesity.

There are several studies on the relationship between breast cancer and using contraceptive pills. Some have shown that using the pills only trivially increased breast cancer risk and this was limited to those who used the pills for a long time. ${ }^{18,19}$ The other studies that have reported inconsistent results are not negligible. ${ }^{14,20-22}$ Bethea et $\mathrm{al}^{20}$ examined the relationship between using contraceptive pills and emergence of breast cancer and found that using contraceptive pills and the term of using the pills were significantly related to development of breast cancer in African American women. Marchbanks et al. ${ }^{14}$ studied women ranged from 35 to 64 years old and found no significant relationship between breast cancer risk and using contraceptive pills. Veisy et al. ${ }^{21}$ found a significant relationship between the term of using contraceptive pills and breast cancer, while Zare et $\mathrm{al}^{22}$ found a that using the pills significantly decreased risk of breast cancer.

Some results show that the use of the pills has no significant impact on increasing risk of breast cancer. Other evidences confirm their carcinogenic effect. Following national family planning programs in Iran, OCPs have been widely used by women in reproductive ages. Although OCPs were considered safe in many cases, some complications are rarely reported and its prescription is contraindicated in some disorders. ${ }^{23}$ In most references, $\mathrm{OCP}$ is one of the probable predisposing factors for breast cancer. ${ }^{20,21}$ Since there are no studies supporting a definite relationship between $\mathrm{OCP}$ and breast cancer in Iran, the present study was conducted to confirm this theory.

\section{MATERIALS AND METHODS}

A case-control study was used to determine the correlation of oral contraceptives pills on breast cancer. All studies from June 2000 to June 2015 were assessed. Inclusion criteria: case-control studies, the study in one of the provinces of Iran in which the risk of breast cancer following use of contraceptive pills are reported. We also used all of studies which corresponding CI 95\%, ORs were reported, and calculation was possible. Exclusion criteria: ecologic, cohort, and cross-sectional studies which corresponding $95 \% \mathrm{CI}$, OR were not reported and calculation was not possible.

Search strategy: Published papers were extracted in six reliable Latin databases namely Cochrane, PubMed, Google, Google Scholar, Scopus, and Science Direct. Persian databases like SID, IranMedex, and Magiran were also used. For the selection of the word to search, the PICO criterion was used. P is population of women in fertility age, I or intervention is the use of oral contraceptives, Cor comparisons are the controls that do not use contraceptive pills, and $\mathrm{O}$ is outcome. Two Iran researchers were dedicated to searching studies to ensure the correct selection of articles. ${ }^{24}$ In searching electronic databases, all articles were extracted, thereafter duplicated ones were excluded.

The articles were searched using the following keywords in Farsi and English: "Breast cancer", "Oral Contraceptive Use", "Pills", "Iran", and their combinations.

Based on the inclusion and exclusion criteria, headlines and abstracts, full texts of articles, and finally favorite articles were chosen. In the form of data extraction (in Excel), author's last name, year of publication, place of the study, age, sample size, cases and control, and OR (95\% CI) were extracted. Extracted data was entered into Microsoft Excel. For data analysis, STATA 12 was used. Two statistical models (fixed and random effect) with CI of 95\% were used with regard to the heterogeneity of studies (Cochran's Q-test, Higgins \& Theompson $\mathrm{I}^{2}$ ) in data analysis. To assess the publication bias, Begg's and Egger's tests were used. ${ }^{25}$ 
Assessment of the quality of studies: To assess the quality of studies, Strengthening the Reporting of Observational Studies in Epidemiology (STROBE) checklist was used. STROBE checklist includes 24 items. These items include: exact point to the study plan, stating precise way for measuring exposure and outcome, referring to calculation method of sample size and a flowchart of selecting subjects, referring to the time of data collection, and referring to the time of arrival and departure criteria. Thereafter, studies were divided into three groups: lot orientation, middle, and low. ${ }^{26}$ In this study, STROBE tool was used to assess the quality of studies for all observational studies. Also, quality assessment was based on expert opinion.

In total, 290 articles were initially found and 213 articles were excluded in the initial evaluation. In the next step, 77 articles were entered but 51 articles were excluded because of low quality of reports or failure to report the results. The final assessment was performed on 26 remaining articles in which 24 were case-control and two were population based studies. In these 26 articles, the number of cases, controls, and exposures were extracted and the OR was calculated using these values.

\section{RESULTS}

Evaluation was carried out for 26 articles ( 24 were case-control studies and 2 were population based case-control studies). ${ }^{21,22,27-50}$ Studies were evaluated with 460,260 participants during 2001 to 2015. The mean age of patients in the control group and case group was 47.81 and 46.13 years old, respectively. The least obtained OR (0.278) in different studies is related to Hosseinzadeh et $\mathrm{al}^{47}$ while the most OR (5.714) is related to Kihanian et al. ${ }^{35}$ (Table 1). In the results of meta-analysis and use of random model, overall estimate of OR for the effect of OCPs on breast cancer is 1.521 ( $\mathrm{CI}=1.25-1.85$ ) (Table 2). The ORs were extracted from different studies and according to exposures in the case and control group. The random effect model and fixed model were used. Heterogeneity in studies was carried out by two indexes and $\mathrm{I}^{2}$ Cochran's Q statistics, Heterogeneity test was used to evaluate the null hypothesis that all studies were evaluated for similar effects. Heterogeneity effect was determined by using chi-square $\mathrm{I}^{2}$, which provides the contradiction between studies. It determines that changes in studies are the result of the heterogeneity, not by chance. $\mathrm{I}^{2}$-value greater than $50 \%$ showed

Table 1. Study characteristics of published population base study and case-control studies on breast cancer and oral contraceptive pills in the meta-analysis

\begin{tabular}{|c|c|c|c|c|}
\hline Author' name & Province & Publication year & Samples size & Study \\
\hline Razmara et al. $^{29}$ & Ahvaz & 2010 & 394 & Case-control \\
\hline Yavari et $\mathrm{al}^{30}$ & Tehran & 2006 & 606 & Case-control \\
\hline Ebrahimi et al. $^{31}$ & Tehran & 2002 & 621 & Case-control \\
\hline Nojomi et al. $^{32}$ & Tehran-mashhad & 2004 & 570 & Case-control \\
\hline Tehranian et al. $^{33}$ & Tehran & 2009 & 624 & Case-control \\
\hline AttarParsaei et al. $^{34}$ & Tabriz & 2001 & 323 & Case-control \\
\hline Kihanian et $\mathrm{al}^{35}$ & Mazandran & 2010 & 120 & Case-control \\
\hline Holakoei et al. $^{36}$ & Mazandran & 2006 & 750 & Case-control \\
\hline Adib et $\mathrm{al}^{37}$ & Rasht & 2012 & 189 & Case-control \\
\hline Lotfi et $\mathrm{al}^{38}$ & Yazd & 2008 & 160 & Case-control \\
\hline Eslamian et al. $^{39}$ & Tehran & 2013 & 285 & Case-control \\
\hline Esfarjani et al. ${ }^{40}$ & Ahvaz & 2010 & 484 & Case-control \\
\hline Kashfi et al. $^{28}$ & Tehran & 2001 & 240 & Case-control \\
\hline Sharif Zadeh et al. ${ }^{41}$ & Birjand & 2011 & 170 & Case-control \\
\hline Emamimeybodi et al. ${ }^{42}$ & Yazd & 2011 & 302 & Case-control \\
\hline Veisy et $\mathrm{al}^{21}$ & Urmia & 2015 & 470 & Case-control \\
\hline Montazeri et al. $^{43}$ & Tehran & 2008 & 232 & Case-control \\
\hline Ghiasvand et $\mathrm{al}^{44}$ & Shiraz & 2011 & 938 & Case-control \\
\hline Sepandi et al. $^{45}$ & Shiraz & 2014 & 11,850 & Case-control \\
\hline Motie et $\mathrm{al}^{46}$ & Golestan & 2011 & 206 & Case-control \\
\hline Zare et $\mathrm{al}^{22}$ & Tehran & 2013 & 24,477 & Case-control \\
\hline Hosseinzadeh et $\mathrm{al}^{47}$ & Tabriz & 2014 & 420 & Case-control \\
\hline Ghorbani et al. $^{48}$ & Isfahan & 2015 & 647 & Case-control \\
\hline Tazhibi et al. ${ }^{49}$ & Isfahan & 2014 & 257 & Case-control \\
\hline Ehsanpour et $\mathrm{al}^{27}$ & Esfahan & 2013 & 525 & Case-control \\
\hline Pourzand et al. $^{50}$ & Tabriz & 2013 & 400 & Case-control \\
\hline
\end{tabular}


Table 2. Pooled results for 24 case-control and 2 population base studies of breast cancer and oral contraceptive pills

\begin{tabular}{|c|c|c|c|}
\hline Study (first author, year ${ }^{\mathrm{a}}$ ) & OR & $95 \% \mathrm{CI}$ & $\begin{array}{c}\text { Weight } \\
(\%)\end{array}$ \\
\hline Montazeri $(1996)^{43}$ & 1.078 & $0.631-1.841$ & 3.72 \\
\hline AttarParsaei $(1998)^{34}$ & 5.265 & $2.919-9.495$ & 3.51 \\
\hline Tehranian $(1998)^{33}$ & 2.830 & $1.887-4.245$ & 4.22 \\
\hline Kashfi $(1999)^{28}$ & 1.330 & $0.787-2.246$ & 3.76 \\
\hline Ebrahimi $(1999)^{31}$ & 0.857 & $0.385-1.910$ & 2.77 \\
\hline Nojomi $(1999)^{32}$ & 1.522 & $1.043-2.221$ & 4.32 \\
\hline Tazhibi $(1999)^{49}$ & 0.571 & $0.266-1.226$ & 2.89 \\
\hline Yavari $(2004)^{30}$ & 1.452 & $1.053-2.001$ & 4.52 \\
\hline Holakoei $(2004)^{36}$ & 1.095 & $0.804-1.492$ & 4.56 \\
\hline Esfarjani $(2004-2005)^{40}$ & 1.279 & $0.812-2.014$ & 4.03 \\
\hline Motie $(2004)^{46}$ & 1.794 & $1.026-3.138$ & 3.63 \\
\hline Kihanian $(2004)^{35}$ & 5.714 & $2.449-13.336$ & 2.62 \\
\hline Sepandi $(2004)^{45}$ & 1.086 & $0.816-1.444$ & 4.64 \\
\hline Ghiasvand $(2005)^{44}$ & 1.513 & $1.167-1.960$ & 4.72 \\
\hline Lotfi $(2006)^{38}$ & 0.532 & $0.280-1.011$ & 3.32 \\
\hline Emamimeybodi $(2006-2008)^{42}$ & 1.933 & $1.190-3.142$ & 3.91 \\
\hline Sharif Zadeh GR $(2006-2008)^{41}$ & 0.788 & $0.429-1.444$ & 3.45 \\
\hline Zare $(2007)^{22}$ & 0.660 & $0.449-0.970$ & 4.29 \\
\hline Razmara $(2008)^{29}$ & 1.508 & $1.012-2.246$ & 4.24 \\
\hline $\operatorname{Adib}(2009)^{37}$ & 2.395 & $1.334-4.300$ & 3.53 \\
\hline Ghorbani $(2010)^{48}$ & 0.856 & $0.451-1.624$ & 3.32 \\
\hline Pourzand $(2010)^{50}$ & 1.244 & $0.696-2.222$ & 3.55 \\
\hline Ehsanpour $(2011)^{27}$ & 2.251 & $1.534-3.304$ & 4.30 \\
\hline Eslamian $(2011)^{39}$ & 2.555 & $1.516-4.307$ & 3.77 \\
\hline Hosseinzadeh $(2011)^{47}$ & 3.593 & $2.332-5.535$ & 4.11 \\
\hline Veisy $(2013)^{21}$ & 2.110 & $1.444-3.083$ & 4.31 \\
\hline Dersimonian + Laird pooled OR & 1.521 & $1.250-1.850$ & 100.00 \\
\hline
\end{tabular}

${ }^{a}$ All of year are years of study and collection data.

inconsistency among studies (heterogeneity). In this study, according to the index of heterogeneity, $\mathrm{I}^{2}=79.5 \%$ and $P<0.001$, the random effect model as well as Dersimonian and Laird were used. The amount of integrated OR was 1.521, this indicates that the chance of exposure was $52 \%$ more in the exposure group than in the control group ( $P=0.001$ ) (Fig. 1). To assess the publication bias, Egger's and Begg's tests were used (Fig. 2).

\section{DISCUSSION}

This study investigated the relationship between the consumption of OCPs and breast cancer. To this end, 26 studies were investigated. The result indicates that using these pills increases the risk of breast cancer up to 1.52 times.

A meta-analysis study by Kahlenborn et al. ${ }^{51}$ on 34 case/control studies showed that OR of breast cancer increased by 1.19 times in the women who used contraceptive pills. In addition, results of the present study indicated that using contraceptive pills for more than 4 years increased OR of breast cancer by 1.52 times. Consistently, Nelson et al. ${ }^{11}$ conducted a meta-analysis study on 61 studies and examined 8 factors. The 12 studies showed that using the pills increased the risk of breast cancer by $30 \%$ times (relative risk $=1.30, \mathrm{CI}=1.13-1.49$ ).

Moreover, a case-control study by Bethea et $\mathrm{al} .^{20}$ estimated the relationship between OCP usage and breast cancer in African-American women. The results confirmed that $O R$ of breast cancer in women who used the pills for more than five years was equal to 1.46 . To create a wide perspective, all studies conducted in Iran on the relationship between using contraceptive pills and breast cancer were examined by the present study.

Several assumptions about the relationship between the use of oral contraceptives and breast cancer have been proposed. The first assumption is that breast cancer is caused by the increase of estrogen in the body, which is caused by two factors. One is that oral contraceptives are mainly composed of estrogen and progesterone, another factor is numerous pregnancies for more exposure with female hormones. ${ }^{18}$ Hence, these pills are likely to increase estrogen levels and then enhance the risk of breast cancer. Another mechanism justifies the impact of high levels of estrogen on the incidence of breast cancer after using pills; reduction and control of estrogen levels is possible by doing physical activities. Those who exercise while using these pills are less exposed to the increase of the level of estrogen and also incidence of breast cancer. ${ }^{52,53}$

The next assumption is that oral contraceptives contribute to a state of weight gain and the use of these pills is a factor for obesity. ${ }^{17}$ These pills by increasing estrogen levels and regional estrogen production are the first causes of overweight. Several studies have shown a relationship between obesity and breast cancer, hence increased estrogen by consumption of these pills, directly leads to overweight and indirectly to breast cancer. ${ }^{5456}$

Other studies also provide additional information about this relationship. ${ }^{22,38,57,58}$ Based on an earlier report, there is a negative relationship between oral contraceptives and breast cancer. Vessey and Painter ${ }^{58}$ in a large cohort study studied 17,032 women and found that these pills not only have adverse effects but also may have positive impact on this disease. This study found that women, who consumed these pills, had less advanced tumors compared to those who did not use such drugs. Moradzadeh et al. ${ }^{59}$ stated that the possibility of protective effects against the disease increases dramatically, when the history of oral contraceptives and family history of breast cancer are simultaneous. Studies by Zare et al. ${ }^{22}$ and Lotfi et al. ${ }^{38}$ confirmed 


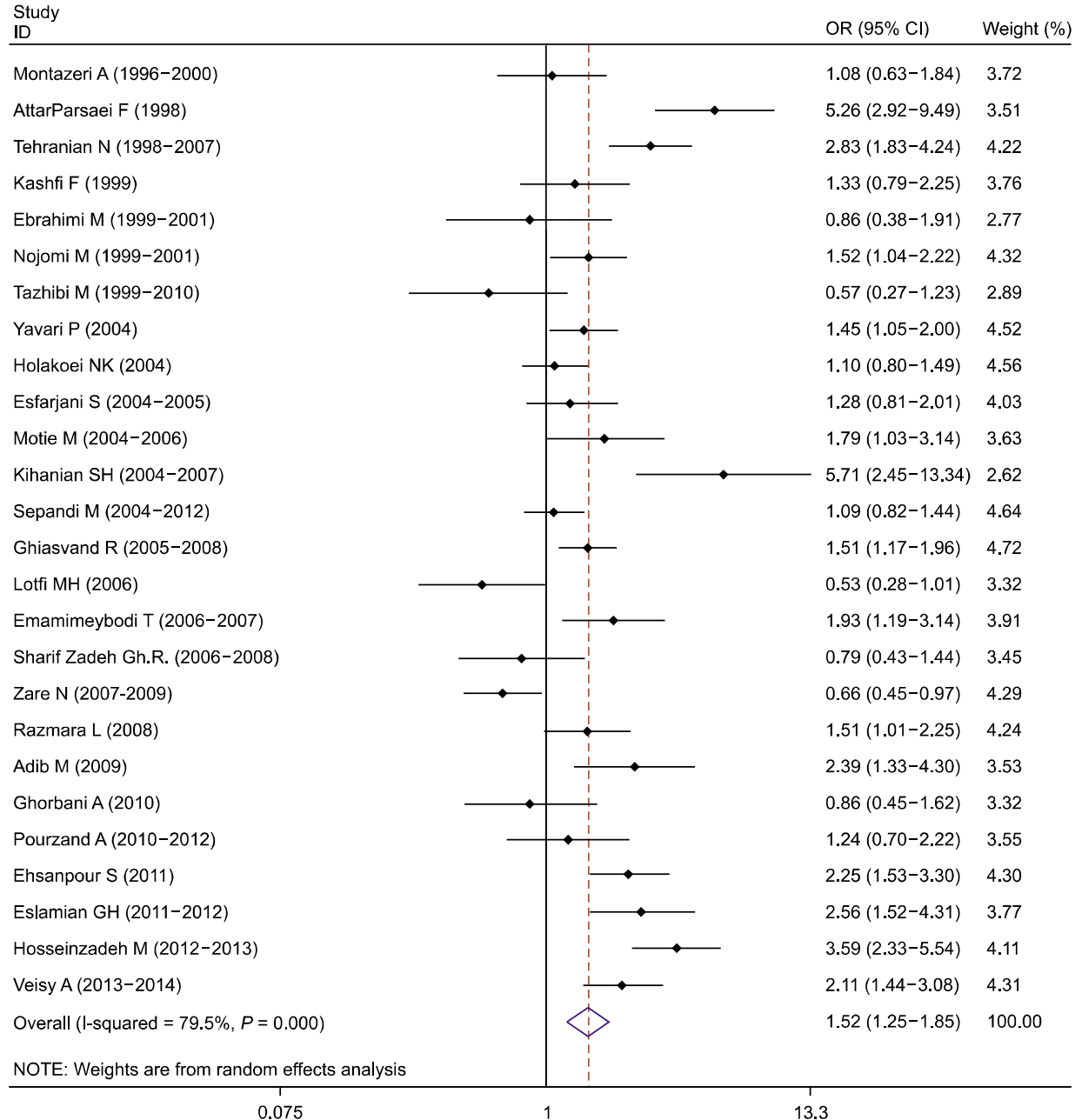

Figure 1. A forest plot of the association between breast cancer and oral contraceptive pills.
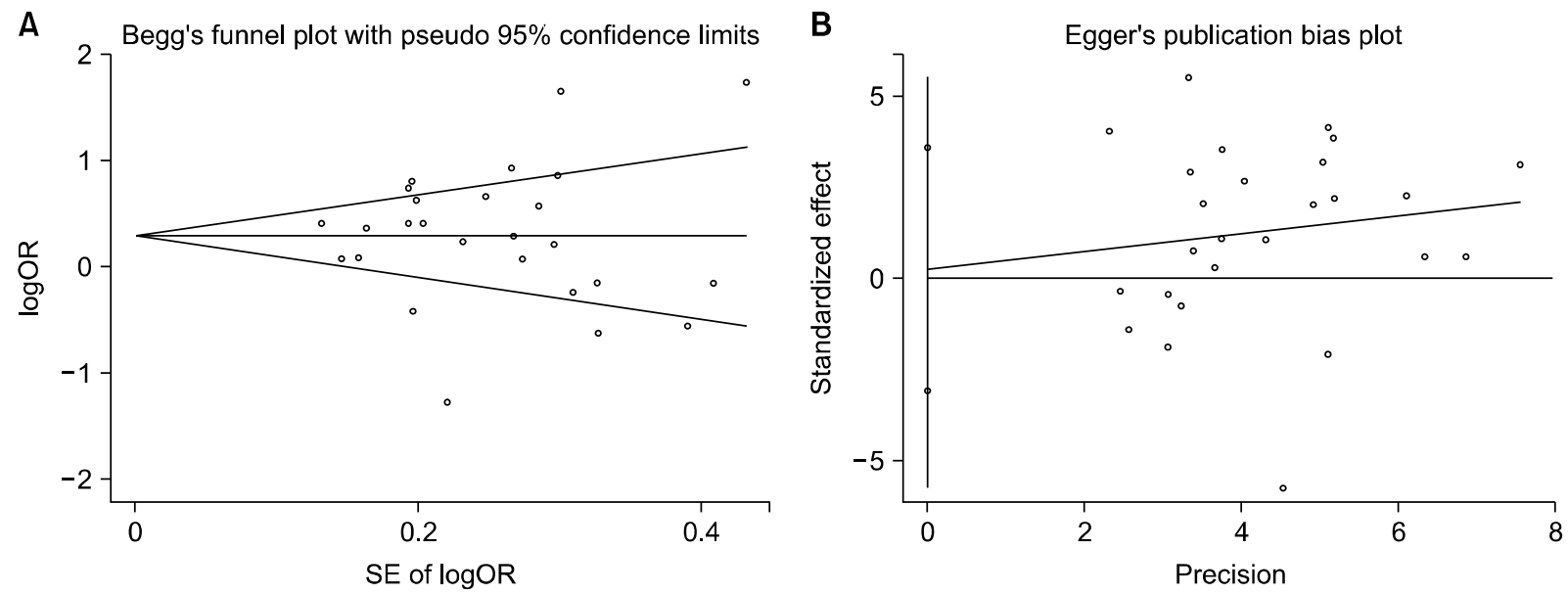

Figure 2. Publication bias which was estimated by Begg's test (A) and Egger's test (B). 
this conclusion. These results are inconsistent with our findings.

Some studies show that there is no relationship between the use of oral contraceptives and breast cancer. Marchbanks et al. ${ }^{52}$ carried out a meta-analysis in 2002 and reviewed 54 studies that represented 4,574 and 4,682 case and control subjects among women from 35 to 64 years of age, including white and black races. They concluded that current or former oral-contraceptive use was not associated with a significantly increased risk of breast cancer. OR for the women who used pills for long-term or continuously was equal to $1(95 \% \mathrm{CI}=0.8-1.3)$ and for the those who had stopped using the pills was equal to $0.9(95 \% \mathrm{CI}=$ 0.8-1.0). ${ }^{52}$ Wingo et al. ${ }^{60}$ found no significant association between using oral contraceptives and mortality rate caused by breast cancer. That is, using OCPs was not effective on increase or decrease of the mortality rate caused by breast cancer. In other words, there was no association between using contraceptive pills and breast cancer.

The results of the current study show that OCPs is associated with increased risk of the breast cancer so that the OR of breast cancer in the women used OCPs is 1.5 greater than that in the women who didn't use of pills. Future cohort studies are recommended to evaluate this association with controlling confounding factors like duration of using oral contraceptives, family history of breast cancer, and oral contraceptives.

Although the results indicated that use of OCPs in women increases $O R$ of breast cancer to 1.5, interpreting the data of the OCPs is not easy due to confounding variables, such as duration of using oral contraceptives, family history of breast cancer, and/or other similar factors.

\section{CONFLICTS OF INTEREST}

No potential conflicts of interest were disclosed.

\section{REFERENCES}

1. Howell A, Anderson AS, Clarke RB, Duffy SW, Evans DG, Garcia-Closas M, et al. Risk determination and prevention of breast cancer. Breast Cancer Res 2014;16:446.

2. Davis NM, Sokolosky M, Stadelman K, Abrams SL, Libra M, Candido S, et al. Deregulation of the EGFR/PI3K/PTEN/Akt/ mTORC1 pathway in breast cancer: possibilities for therapeutic intervention. Oncotarget 2014:5:4603-50.

3. DeSantis CE, Fedewa SA, Goding Sauer A, Kramer JL, Smith RA, Jemal A. Breast cancer statistics, 2015: Convergence of incidence rates between black and white women. CA Cancer J Clin 2016;66:31-42.

4. Teegarden D, Romieu I, Lelièvre SA. Redefining the impact of nutrition on breast cancer incidence: is epigenetics involved? Nutr
Res Rev 2012;25:68-95.

5. Chen L, Huang Z, Yao G, Lyu X, Li J, Hu X, et al. The expression of CXCL13 and its relation to unfavorable clinical characteristics in young breast cancer. J Transl Med 2015;13:168.

6. Curado MP, Edwards B, Shin HR, Storm H, Ferlay J, Heanue M, et al. Cancer incidence in five continents, Vol IX. Lyon, IARC Publications, 2007.

7. Ferlay J, Soerjomataram I, Dikshit R, Eser S, Mathers C, Rebelo M, et al. Cancer incidence and mortality worldwide: sources, methods and major patterns in GLOBOCAN 2012. Int J Cancer 2015;136:E359-86.

8. Yip CH. Breast cancer in Asia. Methods Mol Biol 2009;471:51-64.

9. Pourfarzi F, Fouladi N, Amani F, Ahari SS, Roshani Z, Alimohammadi S. Factors affecting preferences of iranian women for breast cancer screening based on marketing mix components. Asian Pac J Cancer Prev 2016;17:3939-43.

10. Tazhibi M, Feizi A. Awareness levels about breast cancer risk factors, early warning signs, and screening and therapeutic approaches among Iranian adult women: a large population based study using latent class analysis. Biomed Res Int 2014; 2014:306352.

11. Nelson HD, Zakher B, Cantor A, Fu R, Griffin J, O'Meara ES, et al. Risk factors for breast cancer for women aged 40 to 49 years: a systematic review and meta-analysis. Ann Intern Med 2012; 156:635-48.

12. Allicock M, Graves N, Gray K, Troester MA. African American women's perspectives on breast cancer: implications for communicating risk of basal-like breast cancer. J Health Care Poor Underserved 2013;24:753-67.

13. Colditz GA, Bohlke K, Berkey CS. Breast cancer risk accumulation starts early: prevention must also. Breast Cancer Res Treat 2014:145:567-79.

14. Marchbanks PA, Curtis KM, Mandel MG, Wilson HG, Jeng G, Folger SG, et al. Oral contraceptive formulation and risk of breast cancer. Contraception 2012;85:342-50.

15. Urban M, Banks E, Egger S, Canfell K, O'Connell D, Beral V, et al. Injectable and oral contraceptive use and cancers of the breast, cervix, ovary, and endometrium in black South African women: case-control study. PLoS Med 2012;9:e1001182.

16. Bassuk SS, Manson JE. Oral contraceptives and menopausal hormone therapy: relative and attributable risks of cardiovascular disease, cancer, and other health outcomes. Ann Epidemiol 2015:25:193-200.

17. Cleary MP, Grossmann ME. Minireview: obesity and breast cancer: the estrogen connection. Endocrinology 2009;150:2537-42.

18. Onsory K, Ranapoor S. Breast cancer and the effect of environmental factors involved. New Cell Molr Biotech J 2011;1:59-70.

19. Beaber EF, Malone KE, Tang MT, Barlow WE, Porter PL, Daling JR, et al. Oral contraceptives and breast cancer risk overall and by molecular subtype among young women. Cancer Epidemiol Biomarkers Prev 2014:23:755-64.

20. Bethea TN, Rosenberg L, Hong CC, Troester MA, Lunetta KL, Bandera EV, et al. A case-control analysis of oral contraceptive use and breast cancer subtypes in the African American Breast Cancer Epidemiology and Risk Consortium. Breast Cancer Res 2015;17:22.

21. Veisy A, Lotfinejad S, Salehi K, Zhian F. Risk of breast cancer in relation to reproductive factors in North-West of Iran, 2013-2014. Asian Pac J Cancer Prev 2015;16:451-5. 
22. Zare N, Haem E, Lankarani KB, Heydari ST, Barooti E. Breast cancer risk factors in a defined population: weighted logistic regression approach for rare events. J Breast Cancer 2013;16:214-9.

23. Javidi Z, Maleki M, Fata A, Nahidi Y. Evaluation of the relationship between pityriasis versicolor and consumption of oral contraceptives. Iran J Obst Gynecol Infer 2008;10:113-8.

24. Whitehead A. Meta-analysis of controlled clinical trials. Chichester, John Wiley \& Sons, 2002.

25. Sutton AJ, Abrams KR, Jones DR, Sheldon TA, Song F. Methods for meta-analysis in medical research. Chichester, John Wiley \& Sons, 2000.

26. Knottnerus A, Tugwell P. STROBE: a checklist to strengthen the reporting of observational studies in epidemiology. J Clin Epidemiol 2008;61:323.

27. Ehsanpour S, Nejad FS, Rajabi FM, Taleghani F. Investigation on the association between breast cancer and consumption patterns of combined oral contraceptive pills in the women of Isfahan in 2011. Iran J Nurs Midwifery Res 2013;18:186-90.

28. Kashfi F, Nikoofar A, Mohammadi R. Fertility risk factors causing breast cancer. J Reprod Infertil 2002;3:38-45.

29. Razmara L, Hekmat K, Talaiezadeh AH, Tahmasebi M, Karandish M. Relationship between fish consumption and decreased breast cancer risk. Sci Med J (AJUMS) 2010;9:307-16.

30. Yavari P, Mosavi MA, Saderalhefazi B, Khodabakhshi R, Mehrabi $\mathrm{Y}$, Madani $\mathrm{H}$, et al. The effects of reproductive factors on the risk of breast cancer, a study case - control. Iranian J Epidemiol 2006;1:9-11.

31. Ebrahimi M, Vahdaninia M, Montazeri A. Risk factors for breast cancer in Iran: a case-control study. Breast Cancer Res 2002; 4:R10.

32. Nojomi MMR, Hosseni N, Hajizadeh E. Relationship between hormonal factors and breast cancer. Hakim Health Syst Res J 2004;7:19-25

33. Tehranian NHF, Hajizadeh E. Evaluation of risk factors for breast cancer In women under 40 years. J Basic Clin Pathophysiol 2009;16:37-44.

34. AttarParsaei F, Golchin M, Asvadi I. Evaluation of the relationship between demographic, social, lifestyle and stressors in women with breast cancer. Med J Tabriz Univ Med Sci Health Serv 2001;2:15-22.

35. Kihanian SH, Ghafari F, Tatokian Z, Shormij R, Saroei M. Survey risk factor of breast cancer at RAMSAR, TONKABON. Qazvin Univ Med Sci 2010;14.

36. Holakoei N, Ardlan A, Mahmoudi M, Motavalian A, Yahyapour Y. Study of risk factors for breast cancer in Mazandaran province in 1383. J School Public Health Ins Public Health Res 2006;4:27-36.

37. Adib M, Ghanbari A, Pouralizadeh M, Kazemnejad E. Study risk factors related to medical history, lifestyle and Health behaviors of women with breast cancer patients Razi Hospital in the city of Rasht in 1388. IJOGI 2012;15:17-26.

38. Lotfi $\mathrm{MH}$, Charkhatti S, Shobairi S. Breast cancer risk factors in an urban area of Yazd City-Iran, 2006. Acta Medica Iranica 2008;46:258-64

39. Eslamian G, Amiri S, Shakeri M. Dietary fiber, glycemic index, and glycemic load in relation to breast cancer in Iran. Thrita 2013;2:82-8.

40. Esfarjani S, Ahvazi N, Doberjovi M, Ashrafizadeh S. Comparative study of some breast cancer risk factors in patients with breast cancer and leukemia in Ahvaz Shafa Hospital. Scientific Med
J(AJUMS) 2010;9:263-70.

41. Sharif Zadeh GR, Hosseini M, Kermani T, Ataiee M, Akhbari SH. Breast cancer and the related factors: a case control study. J Birjand Univ Med Sci 2011;18:191-9.

42. Emamimeybodi T, Absalan A, Daneshbodi H. Study on the relationship between breast cancer and female endocrine conditions, hormone therapy and oral contraceptive usage among women in Yazd, Iran during 2006-2007. Middle East J Sci Res 2011;8:34-9.

43. Montazeri A, Sadighi J, Farzadi F, Maftoon F, Vahdaninia M, Ansari $\mathrm{M}$, et al. Weight, height, body mass index and risk of breast cancer in postmenopausal women: a case-control study. BMC Cancer 2008;8:278.

44. Ghiasvand R, Maram ES, Tahmasebi S, Tabatabaee SH. Risk factors for breast cancer among young women in southern Iran. Int J Cancer 2011;129:1443-9.

45. Sepandi M, Akrami M, Tabatabaee H, Rajaeefard A, Tahmasebi S, Angali KA, et al. Breast cancer risk factors in women participating in a breast screening program: a study on 11,850 Iranian females. Asian Pac J Cancer Prev 2014;15:8499-502.

46. Motie MR, Besharat S, Torkjazi R, Shojaa M, Besharat M, Keshtkar A, et al. Modifiable risk of breast cancer in northeast iran: hope for the future. a case-control study. Breast Care (Basel) 2011; 6:453-6.

47. Hosseinzadeh M, Eivazi Ziaei J, Mahdavi N, Aghajari P, Vahidi M, Fateh A, et al. Risk factors for breast cancer in Iranian women: a hospital-based case-control study in Tabriz, Iran. J Breast Cancer 2014;17:236-43.

48. Ghorbani A, Moradi A, Gookizadeh A, Jokar S, Sonbolestan SA. Evaluation of relationship between breast cancer and migraine. Adv Biomed Res 2015:4:14

49. Tazhibi M, Dehghani M, Babazadeh S, Makkarian F, Tabatabaeian M, Sadeghi M, et al. Hormonal and reproductive risk factors associated with breast cancer in Isfahan patients. J Educ Health Promot 2014;3:69.

50. Pourzand A, Farajkhah H, Azhough R, Fakhree MBA. Breast cancer risk factors among women without family history in North West of Iran. Life Sci J 2013;10.

51. Kahlenborn C, Modugno F, Potter DM, Severs WB. Oral contraceptive use as a risk factor for premenopausal breast cancer: a meta-analysis. Mayo Clin Proc 2006;81:1290-302.

52. Marchbanks PA, McDonald JA, Wilson HG, Folger SG, Mandel MG, Daling JR, et al. Oral contraceptives and the risk of breast cancer. N Engl J Med 2002;346:2025-32.

53. Coyle YM. Physical activity as a negative modulator of estrogen-induced breast cancer. Cancer Causes Control 2008;19: 1021-9.

54. Scheen AJ, Beck E, De Flines J, Rorive M. Obesity, insulin resistance and type 2 diabetes: risk factors for breast cancer. Rev Med Liege 2011;66:238-44.

55. Stephenson GD, Rose DP. Breast cancer and obesity: an update. Nutr Cancer 2003;45:1-16

56. Dignam JJ, Mamounas EP. Obesity and breast cancer prognosis: an expanding body of evidence. Ann Oncol 2004:15:850-1.

57. Ozmen V, Ozcinar B, Karanlik H, Cabioglu N, Tukenmez M, Disci $\mathrm{R}$, et al. Breast cancer risk factors in Turkish women: a University Hospital based nested case control study. World J Surg Oncol 2009;7:37.

58. Vessey M, Painter R. Oral contraceptive use and cancer. Findings in a large cohort study, 1968-2004. Br J Cancer 2006;95:385-9. 
59. Moradzadeh R, Hasanzadeh J, Rajaaeifard AR, Tahmasebi S, Golmohammadi P. Investigation on gene-environment interaction using breast cancer data a case-only and case-control designs. J Rafs Univ Med Sci 2011;10:267-78.
60. Wingo PA, Austin H, Marchbanks PA, Whiteman MK, Hsia J, Mandel MG, et al. Oral contraceptives and the risk of death from breast cancer. Obstet Gynecol 2007;110:793-800. 